\title{
Tracing Tradition: A Case Study of Child Sacrifice in Uganda
}

\author{
Abigail McCrary \\ Spring 2012 School for International Training Development Studies, Uganda \\ Email address: amccrary@nd.edu
}

\begin{abstract}
In the past decade, there has been an emergence in the practice of child ritual murders, which have surged in prevalence since 2006. An issue which effects both urban and rural areas of the country, there are numerous variables which are understood to be attributing factors and reasons which motivate people to participate in the practice, despite efforts of inhibition put in place by communities from both governmental and non-governmental angles.
\end{abstract}

Keywords: Child sacrifice; tradition; murder

\section{INTRODUCTION}

This study aims to examine the cultural context surrounding child sacrifice in Uganda, focusing on the recent time frame between its emergence in 2006 and today. A large component of the study was in assessing the statistical prevalence of cases of child sacrifice, as well as the causal factors. The larger goal of the research was to use the information gathered in order to make recommendations for improvement on a governmental, legal, and community-wide scale. The research was carried out independently, though the student-researcher was simultaneously holding an intern position at the Uganda Human Rights Commission, an enabling factor which provided the researcher with further legitimization and authority for the purpose of interviews. The study established that the measures in place and institutions responsible were being underutilized, and the issue was not being fully dealt with on a causal, root level. The researcher found some level of misperception among the public in regards to what constitutes child sacrifice as distinct from child murder, as well as in understanding of the perpetrators of the practice. The paper concludes by proposing changes could be implemented to address the deeper underlying issues regarding the practice.

It is impossible for development to occur on a significant scale until people have access to their basic needs - primary essentials required to live, the most obvious of which is life itself. The recent emergence of a trend of ritually killing children in Uganda is a practice which inhibits this very rights - the right to live and to the security of safety for one's own life and that of one's children.

This paper is based on research which examined the various understandings of the practice and to document and interpret the deeper factors contributing to the practice, which are not limited to one geographical area within Uganda. The study intended to make 
recommendations for improving upon the existing measures to deal with child sacrifice and methods of addressing the underlying motivations for the practice. This study was based in Kampala and carried out in a six-week period from March to May of 2012. Interviews were conducted with various individuals and organizations based on their interaction and familiarity with the topic of child sacrifice. The paper begins with a background of the practice, both crossculturally and within Uganda, to create a framework for the place of child sacrifice here and now. The objectives set the stage for the subsequent interpretation and analysis, as well as presentation and discussion of the findings. Finally, the conclusion and recommendations section summarizes the overarching challenges faced in response to this practice, measures which are being taken to deal with it, as well as specific suggestions for the various stakeholders.

\section{BACKGROUND OF THE STUDY}

\section{Global and Historical Context}

Human sacrifice is widely understood to indicate the ritualistic killing of people for the purpose of pleasing, propitiating, or forcing a god or supernatural being in the hopes of achieving a desired result. Distinct from prayers, which offer a form of communication through praise or intentions to a deity, sacrificial offerings take the form of objects of value which hold personal or symbolic significance. The gods or spirits may be offered the most prized foods, tools, weapons, or gems. However, blood sacrifice is largely regarded as the most powerful method of appeasing the gods in numerous cultures and religions worldwide. ${ }^{1}$ Many societies throughout time have engaged in both human and animal sacrifice, though the historical trend has been a sharp reduction in the former. The sacred sanguinary substance is believed to "revivify divinity and so give force to its rites" (Dennis McCarthy, 1969: 166). Child sacrifice is one subset of human sacrifice, and children are valued highly as sacrificial offerings (Michael Newton, 1996: 104).

As Theophrastus postulated, human sacrifice is generally understood to be the historical precedent of animal sacrifice (Theophrastus et al., 1964: 172). Dating back to the $18^{\text {th }}$ dynasty in Ancient Egypt during the reign of Amenhotep II, "proof exists of...the burying of children or adults under new buildings. Infants bodies were discovered in foundations laid as late as the twenty-second dynasty" (Davies, 2000: 37). Greek mythical traditions recount "ritual killings of human beings" and "judgments associated with human sacrifice in Greek thinking" (Baudy, 1996). Evidence has been discovered which indicates group sacrifice of children by the Aztec culture in what it today Mexico (Thomson Reuters, 2007). The Old Testament too associates sacrifice, blood, and covenant in Exodus 24:5-8, and of course the New Testament's theme of Jesus sacrificing his body and shedding blood (John 19:34) so that humanity may attain salvation, exemplifying the larger belief that "in the blood is life" (Leviticus 17:14).

As seen in these examples, along with many others, there is persuasive evidence to indicate that the sacrificial impulse which can be seen cross-culturally throughout history has played an important role in society. The power that individuals and cultures have attributed to the practice of sacrifice, particularly to human sacrifice, over time cannot be underestimated or forgotten.

\footnotetext{
1 "Sacrifice." Encyclopedia of Death and Dying. Web. 01 May 2012. <http://www.deathreference.com/Py Se/Sacrifice.html>.
} 


\section{Cultural Background in Uganda}

In Uganda, both historically and presently, the cultural belief in witchcraft and superstition is essential to note, as it is closely tied to the emergence and perpetuation of the practice. In modern times, this knowledge and belief system is closely associated with traditional healers and their practices. The World Health Organization (WHO) defines traditional medicine as "the sum total of knowledge, skills and practices based on the theories, beliefs and experiences indigenous to different cultures that are used to maintain health, as well as to prevent, diagnose, improve or treat physical and mental illnesses ${ }^{2}$. A traditional healer is a person recognized by the community in which he lives as competent to provide health care by using plant, animal and mineral substances and other methods which may be based on social, cultural and religious backgrounds, as well as knowledge and attitudes that are prevalent in the community regarding physical, mental and social wellbeing and the causes of disease and disability. ${ }^{3}$

Despite its denigration as a primitive practice during the colonial era and the entrenched historical bias toward Western, allopathic health care, traditional medical practices hold an important place in the Ugandan health resource pool and the role that traditional medicine continues to play, even in the context of modernization in Uganda, is extensive. Its medical and cultural significance, as well as the inaccessibility of much of the population to modern health care, have facilitated its continued and thriving existence. It is estimated that about $80 \%$ of the population in developing countries, such as Uganda, have its health care needs met through the traditional medicine sector (Bukuluki, 2006: 7). Traditional medicine provides a model which fits with the cultural understanding of supernaturally-originated illness and misfortune. Traditional healers are trained to provide their clients with answers to their problems that have origin in their cultural expectations and socialization process with emphasis put on the connection between the living and the deceased. ${ }^{4}$

This general concept is closely linked to the personalistic belief system which perceives misfortune and illness to be as a result of unseen forces such as ancestors, spirits and enemies (Tabuti et al., 2003). Continuing with this line of argument, misfortune and illness are associated with one's relationship with others they interact with, as well as spirits. Although misfortune and illness may have a physical immediate cause, the ultimate cause is in a number of cases linked to relationships with people and the spiritual world. ${ }^{5}$ Consequently, people may decide to go to healers to find not only therapy but also the culturally bound answers to their questions arising from circumstances they cannot easily explain (Whyte, 1997).

Sylvia Namutebi, known to many as Maama Fina, the chair person of the traditional healers association has herself stated that "genuine traditional healers sacrifice animals, not human beings" 6 . Sacrifice is, and has been for many years, a large part of Ugandan tradition within communities and most tribes in Uganda traditionally sacrifice livestock for good luck (Margaret Ziribagwat, 2012). However, this does not extend beyond the realm of animals and

\footnotetext{
${ }^{2}$ Traditional Medicine fact Sheet, Accessed on $31^{\text {st }}$ October from http://www.who.int//mediciacenter/factsheet/en/

3 "Traditional Healers." PROMETRA. Web. 1 May 2012.

$<$ http://www.hst.org.za/uploads/files/chapter18_99.pdf $>$.

4 "Traditional Healers." PROMETRA. Web. 1 May 2012.

$<$ http://www.hst.org.za/uploads/files/chapter18_99.pdf>.

5 ibid

6 "Child Sacrifice in Uganda." Combat: Prevention, Protection and Support Against Trafficking. Web. 28 Apr. 2012. <http://www.combattrafficking.eu/content/child-sacrifice-uganda $>$.
} 
into sacrificial rituals of human beings... It is a common belief that the shedding of blood of some kind is warranted to celebrate success, protect someone from misfortune or to chase away evil spirits. In most communities this blood comes from animals such as goats, chickens and cows (Taskforce Report 2009). And although sacrifice is a common phenomenon within African indigenous religious and cultural practices and constitutes an important part of worship, prayer and thanksgiving, it is widely understood in the community of traditional healers that any human sacrifice is not linked directly to indigenous/traditional religious worship and cultural practice (Ministry of Gender, Labour and Social Development, 2009). Traditional healers in Uganda take the united stance that "spiritual healing is to help people prosper, not to bring harm to anyone." "This lack of correlation between traditional culture and the practice of child sacrifice begs the question of origin. Though uncertain, the most common attribution is to foreign influx of culture into Uganda in the traditional healing sector, importing in their traditional beliefs and practices which are not native to this area. Regardless of the explanation, all interviewed agreed that the practice was not rooted in Uganda culture.

\section{METHODOLOGY}

\section{Extensive Literature Review}

Due to the controversial and enigmatic nature of the topic studied, a major portion of the research came from a thorough literature review on various components surrounding the issue. These were used by the student-researcher to contextualize and verify the information gathered through interviews. A significant portion of the research came from a newspaper review, which was juxtaposed with police records, to discern numerically the prevalence of child sacrifice. The disparity found within this review, which will be elaborated on further in this paper, became a point of discussion and analysis in itself. Additionally, a number of secondary sources were helpful in determining the legal framework into which child sacrifice was placed, as well as the place for the practice in both the modern and historical dialogue of traditional healing in Uganda.

\section{Formal and Informal Interviewing}

Participants were strategically chosen for interview in that they ensured variation in goals, methods, and activity locations. Individuals involved in both the governmental, nongovernmental, public, and academic sectors were interviewed as a means of identifying the ideology and history behind the practice, the awareness-level of the population on the practice, and the methods in place to deal with the cases both preventatively and responsively. Though there was no single questionnaire posed to participants queried, as the intention was to gather qualitative data, and extract as much specific information regarding the various angles from which to address this practice in the limited time provided.

All interviews were audio recorded in order that the student-researcher most fully engage in the interview discussions and additionally so that minute details would not be missed in transcription and post-interview analysis. The researcher informed each interviewee regarding the details of the research and the reason behind audio-recording. Each interviewee who was audio recorded agreed to this by his or her own free will. All audio recordings were erased at the finish of the study for protection of the interviewee's privacy. When translations were

\footnotetext{
7 "Maama Fina." New Vision [Uganda] 20 Apr. 2012, Pakasa sec.: 30.
} 
necessary for informal interviews, the researcher made every attempt to have the conversation translated word-for-word.

Additionally, no interviewee was pressured to respond to any question with which he or she felt uncomfortable. The setting of most of the interviews was generally formal in nature, though the student-researcher made a concerted effort to create a friendly and comfortable rapport with the interviewee before the interview commenced. This was further aided by the fact that each interview took place in familiar surroundings for the interviewee. See the primary sources section of the works cited page for a detailed list of the interviewees.

\section{Analysis of Research Methods}

Though the extensive literature review was invaluable in creating a contextual framework from which to place the information gathered, informant interviews were essential to the followup phase of research; they were used to verify the information gathered, and to cross-check whether the theoretical methods of prevention and follow-up were put into practice. Though there was no single series of questions, there were some which were consistent throughout the interviews, and all followed a similar formal. The many different organizations and perspectives which the interviewees represented were chosen in the hopes of elucidating alternative perspectives and to triangulate the information from other interviews. Using the data collected, the information was sorted, synthesized, and assembled into relevant categories according to the theme of the study and derived from the objectives laid out initially.

\section{Ethical Considerations}

In an effort to conduct ethical research, all participants and institutions were given an explanation of research objectives and informed of their power to terminate the interview at any time or refuse to answer any question. On an individual basis, a consent form was released by the student-researcher and signed by the client, upon understanding all terms and conditions of this educational study. Confidentiality and anonymity of respondents were respected based on the preferences indicated by interviewees. The student-researcher ensured that proper steps were taken to avoid danger or harm to participants and informants, as the safety of the interviewees was of the highest priority.

\section{FINDINGS AND DISCUSSION}

\section{Analysis of Statistical Summary}

A major point of divergence in the research proved to lie in the numerical representations of cases, and statistics on the prevalence of child sacrifice. The two opposing forces which composed this difference were Uganda Police Force and the media, with the media representing over double the number of definitive cases addressed by the police in the same time span (108 versus 50).

There is "no independently verified information on the exact number of children ritually murdered each year" (UNICEF, 2009). This numerical disparity between the 83 cases taken from newspaper articles alone and the 49 cases documented as certain cases of child sacrifice is stark and a distinction worth taking note of. There are numerous factors which can account for this difference, including inefficiency of the police force, fear of reporting to the police, glorification and misattribution of stories by reporters. Mirina Nanziri, the programs coordinator for the Empower and Care Organization stated in response to a question of the lack of police records that many of the cases "are not documented because some people lack 
evidence, and to those who know the truth, they fear to be taken as suspects. To make the follow-up, it can take your time, it can cost you a lot, yet it's not going to be taken to another level. Even some people tend to bribe the police. It's one problem that we are facing. " Police records indicate that interactions with survivors of child sacrifice and associated vices such as fear of reporting. "People generally fear witchdoctors and say they hold certain powers that are beyond ordinary human beings, so they fear. With that, even discussing child sacrifice openly, people even fear. If you go against them, harm will come to you, so people rather prefer to keep quiet, not speak about these activities" $"$. This could be a major reason behind the disparity in numbers represented in the statistics gathered from newspapers and police reports.

This sentiment is furthered one step by addressing the fear not of the police, but of the witchdoctors themselves. Many people fear that if they "go against [these witchdoctors\}, harm will come to [them], so people rather prefer to keep quiet, not speak about these activities. ${ }^{10}$ ", With such a pervasive culture of witchcraft, as stated in the introduction, many Ugandans fear the spiritual implications which could come from acting out against these individuals who are believed to be intermediaries between these powerful and dark spirits. Even Moses Uganda Police, the commander of the Human Sacrifice and Trafficking Task Force, acknowledges the bias in the number of cases portrayed. In an interview, he stated himself that

\begin{abstract}
"It may not be very accurate, depending on who is reporting, but of course some cases may not be reported to the police. There have been a tendency of the press coming up with highlights so that people can read the newspaper very fast, so some ordinary murders caused by say domestic violence and drug effect, are flashed in the newspapers as child sacrifice, so that is where there are those differences. Additionally, some murders are committed by parents and relatives, and choose to handle it as a family matter and not report it"11.
\end{abstract}

Glamorizing an ordinary case with the garb of child sacrifice is more exciting for readers, despite its level of veracity. Another very important factor which the researcher came across throughout the research was definitional in nature. Sacrifice, by its very definition, reflects the giving up of something which has personal meaning or importance. There must be an attachment to what you sacrifice. It must have value to you but not to another person. You cannot sacrifice what does not belong to you. You cannot go to the market to buy a cow or chicken and then present it as a sacrifice to the spirits. That is an acquired item. A sacrificial object must be something you already possess and value deeply" (Empower and Care Organization, 2012).

However, many of the cases represented in newspaper and police reports are explained as the kidnapping of a completely unrelated child for the purpose of sacrifice. These cases, by their very nature, are more reflective of murder. It is true that the bodies of the children are often found with missing body parts, and this may look ritual upon inspection, but this could also be attributed to organ trafficking. Therefore, I would argue that many of the cases represented statistically do not accurately distinguish between child murders and child sacrifice, which largely misrepresents the numbers. Unfortunately, because in so many cases the

\footnotetext{
${ }^{8}$ Mirina Nanziri, Field Partners Coordinator at Empower and Care Organization, interview by researcher. Mukono. (April 19, 2012).

${ }^{9}$ Santos Lubega, founder of The Gideon Foundation Against Child Sacrifice, interview by researcher. Makindye, Kampala, (April 18, 2012).

10 ibid

${ }^{11}$ Moses Uganda Police, commander of the Anti-Human Sacrifice and Trafficking Task Force, interview by researcher, Kololo, Kampala, (April 12, 2012).
} 
perpetrators cannot be identified, it is difficult to gage the differences numerically. This also calls for the desperate need for further exploration on the organ trade in Uganda.

\section{Factors contributing to child sacrifice/murder}

There are a number of factors promoting or perpetuating the practice of child sacrifice which have economic, social, and structural basis. These include but are not limited to a desire for wealth, poverty, inadequate mechanisms for child protection at the community and family levels, fear or spiritual repercussions, superstitious beliefs, and critical definitional nuances between sacrifice and murder.

The overarching theme of wealth is an important influence, exacerbated with everincreasing globalization and economic growth in Uganda. People earn respect and recognition in their communities materialistically, due to the wealth they possess, and the adoption of interpreting wealth as a value has driven some people to seek means of acquiring possessions at all costs. This value has, in the case of child sacrifice, overridden the value that emphasized the sanctity of life. Some argue that the prevalence of child sacrifice reflects its close association to business. Spiritually, this practice follows the theory of death and blood and symbolically a "symbol of fertility, a source of new life" (McCarthy, 1969: 176). However, in this case it is economic life. Sacrifice acts as a form of exchange with the gods, a sort of currency in an age before the establishment of a monetary system. In modern parlance, sacrifice was a way of doing business, in an ever-increasing capitalistic society focused on industry and wealthacquisition. ${ }^{12}$

The "business" of child sacrifice is beneficial for all parties, all based in profit. From the perspective of the wealthy individuals who seek child sacrifice to be performed for them, the intended end goal is "money. It's very simple. Just for money, Just for material gain. They really and truly believe $100 \%$ that if they kill a child, they will be rich in no time" ${ }^{\prime 13}$. In the case of the witch-doctors and their agents, the promise of "money encourages them to look for children and kidnap them. Most people range from 2-3 million, it varies"14. Everyone involved walks away with either strong expectation for riches or tangible financial gain.

Closely associated with this deep-seated aspiration for wealth is its opposite - poverty. Though it may be the wealthy businessmen from Kampala who organize many of these crimes $^{15}$, the agents who agree to facilitate these transactions often take part on account of desperation for money. Additionally, the cases in which the parents sacrifice their own children can be interpreted to exemplify the deep desire to escape the cycle of poverty.

Another related sector which may be responsible for increased prevalence is the network of support for the child at the family and community level. There is a growing culture of individualism which undermines community child protection structures which we prevalent in the collectivist African society of the past (Anne-Marie Ambert, 1994: 529-543). Parents often will leave their children alone or with other caretakers for the purpose of working just to feed their family. In other words, "poverty leads parents to neglect their duties. They are going somewhere to look for monies so that they can sustain their families. So they give their children

\footnotetext{
${ }^{13}$ Pascal Bogaert, teacher and actitivst against child sacrifice, interview by researcher. Makindye, Kampala, (April 6, 2012).

${ }^{14}$ Mirina Nanziri, Field Partners Coordinator at Empower and Care Organization, interview by researcher. Mukono. (April 19, 2012).

${ }^{15}$ Chris Rogers. "Where Child Sacrifice Is a Business." BBC News. BBC, 10 Nov. 2011. Web. 30 Apr. 2012.

$<$ http://www.bbc.co.uk/news/world-africa-15255357>.
} 
to some other people who are not held responsible about them and are not accountable"16. The long distances the children are expected to travel alone also create environments of vulnerability and danger in doing tasks such as fetching water or walking back from school. In this way, "children become victims of traffickers who kidnap or entice them from their parents or guardians using force, or bribery". ${ }^{17}$

The strong cultural ties to superstition have enormous weight in analysis of the practice of child sacrifice. "From time immemorial, the traditional religious lifestyle of Ugandans, of all tribes in Uganda, was called witch-craft," centered on the "interaction between the supreme god, their ancestral spirits, and witch doctors" (Waswa and Miirima, 2007). This sentiment was further verified through interviews, and explained by Santos Labeja, who said that "for us in Africa, our lives are ruled by interpretation of events. But you in the West, your lives are ruled by processes of things. To you, if there is no rain for example, you know that the tree covers have been depleted, but for us in Africa, we ascribe that to some spirits of ancestors who are preventing the rain from coming. We don't look at what we have done to cause the depletion of the tree covers. And you in the west, you know it. Science dictates your life. In Africa, no."18

This cultural and historical tie is not one which can just be pushed away by the growing pressure towards modernization and globalization. This paradox in itself is one worth noting the fact that traditional healing and beliefs in spirits have continued to thrive alongside Christianity, capitalism and modernity. Rather than portraying dualism with its distinct demarcations between good and evil, the Ugandan concoction of beliefs closely reflect the concept of syncretism, and the way in which people are able to balance opposing forces and ideas both within themselves and their culture on the large scale. Often, themes are Christianity and western methods of success are exhibited, while in reality traditional beliefs and practices may be held in high esteem. This varies distinctly from non-contradictory and non-antagonistic ideas of cultures as distinct and separate (Norval, 1999). Norval addresses precisely this when he argues that cultural identity cannot be seen as closed and positive, but it "exists as fragile and vulnerable - as a hybrid and non pure". Or, according to Mary Douglas' interpretation, rituals can be used as cultural buffers in response to issues which compromise social, and in this case economic, security. They function therapeutically and preventatively against perceived risk and vulnerability (Douglas, 1966).

This translates into the recent emergence of the practice of child sacrifice in Uganda, a practice carried out with the intention of creating or securing wealth and prosperity. Western ideals of success as economically depicted are exported into Uganda at an increasing pace in the last decade, and with them come social values and raised expectations of a good life. In order to keep pace with these appealing foreign standards of life, Ugandans are driven to facilitate them in any way they know how. And playing off the syncretic and fluid cultural beliefs, child sacrifice offers one dramatic form of integration. In other words, it illustrates the connection between the "integration of Africa in the world's economy and the commodification of the human body. ${ }^{19}$ " With increased pressure for financial prosperity, child sacrifice is one method of acquiring these deep desires of the psyche for some Ugandans, integrating traditional methods with modern standards. There is discordance with a background and culture of superstitious beliefs where commerce and capitalism now reign.

\footnotetext{
${ }^{16}$ Mirina Nanziri. (April 19, 2012).

${ }^{17}$ Robby Muhumuza, "Child Sacrifice is on the increase in Uganda." The Daily Monitor,14 ${ }^{\text {th }}$,Aug, 2006.

${ }^{18}$ Santos Lubega, founder of The Gideon Foundation Against Child Sacrifice, interview by Researcher. Makindye, Kampala, (April 18, 2012).

${ }^{19}$ F. Bernault. "Body, Power and Sacrifice in Equatorial Africa." Journal of African History, 47.2 (2006): 207.
} 
The issue of contempt is the truth behind these methods and their foundation in culture. Based on the research undertaken through literature review and primary interviews, the researcher was unable to find any validity to the argument of the practice as a cultural one. Each interviewee expressed exactly the same sentiment:
"No, no the thing is that if you ask them, Ugandan people, you ask where did it start who is the first one they will always deny that it is a Ugandan thing, it is not our culture, we are not the ones. Keep saying it's from another country. They are used to sacrificing animals - goats, chickens - that's very much something they do and they are used to that" 20 .
"In Uganda, child sacrifice is not our culture"21.
"Sacrificing children have come from external forces outside, from outside of Uganda, and the original, traditional spirits do not agree with practices such as these" 22 .
"It is complex because sacrifice has been here in this part of the culture, but the practice of child sacrifice is not part of the culture. But the old concept of sacrifice (of goats, bows, hens) is there in the culture. But child sacrifice is something new" (Bukuluki, 2012).

These interview excerpts represent individuals from different sectors in society, all coming together in agreement that this practice lacks cultural foundation.

One reason which may be linked to the incorrect assumption of the practice as cultural is the fact that the perpetrators are referred to as traditional healers. It is true that there are cases of traditional healers functioning as practitioners of the practice, but this does not equate it with culture or tradition in Uganda. In fact, this is one major point of contention which the researcher encountered - differentiating between traditional healers who abide by these traditional practices, and those who falsely portray themselves as traditional, yet violate the principles set out by legitimate traditional healers in Uganda of spiritual healing as helping, "not to bring harm to anyone." 23 . In literature, a common method of distinction in diction was to term these illegitimate healers who took part in child sacrifice as witch-doctors. And for the sake of this paper, this researcher chooses to use this same verbal tactic.

In curbing the effects of this practice, it is essential to make this distinction between witch-doctors and traditional healers. All witch-doctors are traditional healers, but not all traditional healers or herbalists are witch doctors. The practice of child sacrifice is committed by a small few of the witch doctors, yet inaccurately ascribed to the larger population of traditional healers, most of which have only positive intentions. A recommended solution to this problem lies in the creation of a national database of traditional healers. However, the process of registering traditional healers and of establishing a statutory council in complicated by the sheer size of the potential membership, thus making regulation of any form very difficult. It is true that traditional healers are meant to register with their local government official; however those who are practicing things such as child sacrifice would often choose to forgo

\footnotetext{
${ }^{20}$ Pascal Bogaert, teacher and actitivst against child sacrifice, interview by researcher. Makindye, Kampala, (April 6, 2012).

${ }^{21}$ Mirina Nanziri, Field Partners Coordinator at Empower and Care Organization, interview by researcher. Mukono. (April 19, 2012).

22 James Ssesanga, Traditional Healer, interview by researcher. Makindye Dunga, Kampala. (April 20, 2012).

23 "Maama Fina." New Vision [Uganda] 20 Apr. 2012, Pakasa sec.: 30. Print.
} 
this and perform their rituals and ceremonies without acknowledgement of governmental authority, a problem which needs to be reconciled to successfully control and curb this practice.

\section{CONCLUSIONS AND RECOMMENDATIONS}

There are a number of methods which can be used in order to deal with the problem of child sacrifice, both in the public and government sectors. This researcher recognizes the need for further enforcement and amendment of laws currently in place. The researcher recommends that the government amend the 1957 Witchcraft Act to make a clear distinction between traditional healers and illegitimate posers, as well as create a mandatory database of trained and qualified traditional healers in order to further distinguish them from traditional healers or traffickers (ANPPCAN Uganda Chapter, 2011). According to the commissioner for culture in the MoGLSD, there is lack of a national database for all traditional healers in Uganda (Empower and Care Organization, 2012). "At the district level, the role of the culture officer is to regulate activities of traditional doctors and their ceremonies," ${ }^{24}$ however illegal activities are often performed by individuals who choose to avoid this acknowledgement of local government. Local government structures lack the capacity to monitor these individuals. Therefore, a more organized, enforced, and comprehensive system of regulation is recommended, which would support the legitimate traditional healers, and separate those involved in activities such as child sacrifice.

The Ministry of Gender, Labour and Social Development (MoGLSD) should additionally expand awareness campaigns to inform the public about the practice of human sacrifice and trafficking and the preventative measure which can be taken against it. It is essential to "organize society in such a way to be vigilant and sensitized," perhaps through campaigns on various media. In this same vein, the researcher recommends further emphasis on differentiating between child sacrifice and activities associated with organ trade and child trafficking both in public and government sectors to facilitate the most appropriate proceedings for each specific case, as well as increased statistical clarification. "Trafficking manifests in kidnapping, elopement, and other forms of manipulation of children. It should be observed that some organ trade protagonists may be disguising as traditional healers" (Empower and Care Organization, 2012). It is essential that investigative parties avoid making judgments and assumptions regarding the nature of the crime without first considering all possibilities and scenarios. Trafficking and organ trade have the potential act as compounding phenomena to the practice of child sacrifice and its effects, and an increased level of scrutiny and contextual information would enable more accurate statistics to be gathered on each of the distinct areas. This information is necessary for further preventative action and awareness programs to ensue.

On a community-level, some families in regions which are being effected, in an attempt to curb the prevalence of child sacrifice and prevent harm from coming to their children, are beginning to pierce the ears of their girls and circumcise their boys at a younger age, thus making their child unacceptable for sacrifice. "If someone shed blood, that's not acceptable" and witch doctors will not accept them." - Mirina Nanziri. Though this is one way of dealing with the problem, it does not address the root issues causing it in the first place.

From an educational perspective, the researcher recommends building a capacity of community and school-based structures for prevention and awareness of child's rights

\footnotetext{
${ }^{24}$ Ssewbatya Kaboggoza, Assistant Commissioner of Children's Affairs, interview by Researcher. Ministry of Gender, Labour and Social Development, Kampala, (April 20, 2012).
} 
violations. There are a number of civil society organizations in place to facilitate educational programs such as this, ${ }^{25}$ but there is room for expansion, particularly if programs such as these were to be integrated into governmental curriculum in some form. This exposure and sensitization to dangers posed to children would create awareness among the population effected directly from practices such as these, and this awareness could lead to a decrease in their prevalence through teaching of attentiveness and preventative measures. It is recommended that community and school-based institutions be equipped to intervene both for prevention as well as response in addressing child sacrifice and its place within the context of violations of children's rights.

Retrospectively, it is necessary for there to be improvement in current community and institutionalizes psychosocial interventions for survivors and their families. It is necessary to develop a functioning referral system to ensure that survivors, their families, and the families of victims of child sacrifice are linked to psychosocial support services. These services should be mainstreamed and prioritizes by the MoGLSD, UNICEF, and other civil society agencies. Due to the data found which indicates a disparity in information between the UPF and the media which requires mitigation and clarification, this researcher recommends a greater level of collaboration between the two, perhaps in the form of a partnership with the intention of sharing information gathered on this specific issue. This system could offer benefits to both parties involved - providing an increased flow of information to the police who could be utilized in investigation of cases, but also offering documented cases to the media, and thus facilitating sensitization and awareness of the practice to the public. In this way, an increase of information would flow to both parties, while simultaneously offering a method of validation through crosschecking of facts.

On a root level, this researcher sees one major factor of the practice to be in the lack of a formal insurance policy. Preservation and protection of wealth and business ventures was interpreted to be a major causal factors leading to child sacrifice identified by informants. With an emerging middle class, the desire to control wealth is powerful, and a formal policy of insuring the capital acquired would lead to less uncertainty and curb reliance on dangerous and superstitious practices. With the creation of a financial safety net for Ugandans, this significant underlying factor motivating individuals to take part in the practice of child sacrifice would no longer be necessary, as they would be financially protected through other, more formal means.

\section{Acknowledgement of bias/constraints}

Throughout the course of limited six-week time frame allotted for research and synthesis for this paper, there are a number of factors which must be acknowledged. There is first the broad fact of quantitative research being more inherently biased than qualitative research, because of the interpretive and fluid nature of the methodology. The researcher made the intentional decision not to utilize one universal questionnaire during interviews for the purpose of fully exploiting the particular perspective and angle of the very different contexts the interviewees came from in their analysis and understanding of the practice. This could lead to bias in the lack of regularity and formula to interviews, expressing the qualitative nature of the topic over quantitative. This was mitigated to some extent by literature and other official documents, though many of these carried bias within themselves. For example, the differences in numbers of ritual child sacrifice cases between the police and NGOs. The time in which the research was undertaken was limited and inadequate to fully analyze the broad and multifaceted nature of the study. The intent was to give a broad and comprehensive overview of the

\footnotetext{
${ }^{25}$ Notably Lively Minds and Youth Focus Uganda
} 
practice, but there is a great deal of elaboration that could be done on any one of the cases mentioned in the study. Further study could give greater explanation into any one component of the practice, such as rural understanding and the success of sensitization, human trafficking and the organ trade, education programs for children, the perspective of businessmen in Kampala, religious syncretism, etc.

\section{Further Expansion of Research}

The researcher acknowledges many directions which need further exploration. Because this research was focused more on cultural effects rather than governmental action, a more indepth follow-up could be done specifically these sensitization and awareness campaigns which are portrayed as being in place currently, and their effectiveness in the population. Further analysis of the legal framework in place would be another important factor to delve into, as it effects conviction of the crime, and ways in which it can be improved, and more critical analyses of police action and follow-up are essential. Non-governmental approaches could also be looked at more closely, to see the ways in which these issues are being implemented from the grassroots, community-level perspective. More information could be gathered to create a more comprehensive framework and understanding of the practices of traditional healers in Uganda and their importance in the realms of both culture and the health care system. Research could be undertaken to further look at the issue from the angle of wealthy businessmen, and the ways in which syncretism pervade all socioeconomic realms, and how this effects view of economic and business life cross-culturally.

\section{References}

[1] African Charter on the Rights and Welfare of the Child, OAU Doc., CAB/LEG/24.9/49 (1990)." Web. 31 Mar. 2012. <http://www1.umn.edu/humanrts/africa/afchild.htm>.

[2] Amber Anne-Marie, An International Perspective on Parenting: Social Change and Social Constructs, Journal of Marriage and Family 56(3) (1994) 529-543.

[3] ANPPCAN Uganda Chapter, Child Sacrifice Epidemic during Festival and Election Period, 2012. ANPPCAN Uganda Chapter, "Our Work", Web. 11 Apr. 2012. $<$ http://www.anppcanug.org/>.

[4] Baudy G., Le sacrifice humain en Grèce ancienne by Pierre Bonnechère Review, History of Religions, The University of Chicago Press 36(1) (1996).

[5] Bernault F., Body, Power and Sacrifice in Equatorial Africa, Journal of African History 47(2) (2006).

[6] Bukuluki P., Traditional Healing Practices among the Baganda in the Context of Christianity and Western Medicine, Viennese Ethnomedicine Newsletter 9(1) (2006) 7-19.

[7] Hughes D., Child Sacrifice Emerges as Disturbing Uganda Trend: ABC News, ABC News Network, 25 February 2010.

[8] "Child Sacrifice in Uganda", Combat: Prevention, Protection and Support Against Trafficking, Web. 28 Apr. 2012.

$<$ http://www.combattrafficking.eu/content/child-sacrificeUganda $>$. 
[9] "Child Sacrifice in Uganda", Safe World for Women: Empower and Care Organization, Web. 11 Apr. 2012.

$<$ http://www.asafeworldforwomen.org/partners-in-africa/partnersin-uganda/eaco/studies. html>.

[10] Lively Minds, Child Sacrifice Prevention; Web 28 Apr. 2012. $<$ http://www.livelyminds.org/2_projects/19/child-sacrifice-preventionprogramme>.

[11] Uganda Embassy, Constitution of Uganda; Web, 31 Mar. 2012. $<\mathrm{http}$ ://www.ugandaembassy.com/Constitution_of_Uganda.pdf $>$.

[12] UNICEF, Convention on the Rights of the Child; Web, 28 Apr. 2012. $<\mathrm{http}: / /$ www.unicef.org/crc/>.

[13] Nigel D., Human Sacrifice in History and Today: New York; William Morrow \& Co., 1981.

[14] Douglas M., Purity and Danger: An Analysis of Concepts of Pollution and Taboo, London: Routledge, 2003.

[15] "Empowering Youth", Youth Focus Uganda: Web, 28 April 2012. $<$ http://www.youthfocusuganda.org/empowering.html $>$.

[16] McCarthy D., The Symbolism of Blood and Sacrifice, Journal of Biblical Literature 88(2) (1969) 166-176.

[17] Ministry of Gender, Labour and Social Development, Rapid Assessment on Child Sacrifice in Uganda, 2009.

[18] Newton M., Written in Blood: A History of Human Sacrifice, Journal of Psychohistory 24(2) (1996)

[19] Rogers C., Where Child Sacrifice Is a Business: BBC News. BBC, 10 Nov. 2011. Web, 30 Apr. 2012. <http://www.bbc.co.uk/news/world-africa-15255357>.

[20] "Sacrifice", Encyclopedia of Death and Dying: Web. 01 May 2012. $<$ http://www.deathreference.com/Py-Se/Sacrifice.html $>$.

[21] Whyte, S.R., "Questioning Misfortune, The pragmatics of uncertainty in eastern Uganda:" Cambridge University Press, 1997.

[22] "The Children Act", Uganda Embassy, 1997. Web. 11 Apr. 2012. $<$ http://www.ugandaembassy.com/The_Children_Act.pdf $>$.

[23] Uganda Human Rights Commission, Child Sacrifice Overview. Issue brief. Print.

[24] "Uganda Summary and Analysis", Representing Children Worldwide. Yale Law School, 2005. Web, 11 Apr. 2012.

$<$ http://www.law.yale.edu/rcw/rcw/jurisdictions/afe/uganda/frontpage.htm>.

[25] UNICEF Uganda, Child Sacrifice: Uganda Facts for Reference: UNICEF, 2009. Web. 28 Apr. 2012. <http://www.scribd.com/doc/22142285/Child-Sacrifice-

[26] Theophrastus and Walter Pötscher. Theophrastos Peri Eusebeias: Griechischer Text. Leiden: E. J. Brill, 1964. 
[27] The Universal Declaration of Human Rights, Human Rights Charter, The UN and Human Rights:" UN News Center, UN Web, 31 March, 2012.

$<$ http://www.un.org/en/documents/udhr/>.

[28] Uganda Police Headquarters Criminal Investigations Directorate, Status of the Child Sacrifice Situation: Kampala Uganda, 2011.

[29] Uganda Police, Moses, interview by Researcher: Kololo, Kampala, April 12, 2012.

[30] "Witchcraft Act, Laws of Uganda: Uganda Legal Information Institute, (1957) 124; Web, 02 Apr. 2012.<http://www.ulii.org/ug/legis/consol_act/wa1957122/>.

[31] Ziribagwa Margaret, Human Sacrifice on the Increase: New Vision, 30 Jan. 2010; Web, 28 Apr. 2012. <http://www.newvision.co.ug/D/8/12/708473>. 